\title{
Partial Discharge Characteristics in LLDPE-Natural Rubber Blends: Correlating Electrical Quantities with Surface Degradation
}

\author{
Aulia*, Mohd Hafizi Ahmad ${ }^{\dagger}$, Zulkurnain Abdul-Malek**, Yanuar Z. Arief**, \\ Kwan Yiew Lau** and Novizon*
}

\begin{abstract}
Partial discharges (PD) lead to the degradation of high voltage cables and accessories. PD activities occur due to the existence of impurities, voids, contaminants, defects and protrusions during the manufacture and installation of power cables. Commonly, insulation failures occur at cable joints and terminations, caused by inhomogeneous electric field distributions. In this work, a blend of natural rubber (NR) and linear low density polyethylene (LLDPE) was investigated, and the optimal formulation of the blend that could resist PD was discussed. The experiments were conducted under a constant high voltage stress test of $6.5 \mathrm{kV}$ AC and the magnitude of partial discharge activities was recorded using the CIGRE method II. Pattern analysis of PD signals was performed along with the interpretation of morphological changes. The results showed that the addition of $10 \mathrm{wt} \%$ of NR and 5 $\mathrm{wt} \%$ of Alumina Trihydrate (ATH) provided promising results in resisting PD activities. However, as the NR content increased, more micropores existed, thus resulting in increased PD activities within the samples.
\end{abstract}

Keywords: Partial discharge, Natural rubber, PD pattern, Linear low density polyethylene

\section{Introduction}

Partial discharge phenomenon is a pre-breakdown phenomenon that arises due to the presence of imperfections in an insulator. Imperfections such as contaminants and impurities in an insulator diverges the electric field across the insulator, resulting in a local stress enhancement at the imperfection sites. This leads to performance deterioration of the insulator [1-4].

Partial discharges commonly occur in power cables such as those made from cross-linked polyethylene (XLPE) [58]. Therefore, analyses of partial discharge activities within power cables have to be carried out periodically to monitor the insulation performance of the cables. These include partial discharge analyses for cable terminations, which are often considered as weak insulation points with the highest partial discharge activities [9].

Recently, the use polymer blends and composites have drawn increasing interests from the dielectrics community for enhancing partial discharge performance of insulators. With an appropriate combination of different materials, the resulting materials are expected to offer better insulation performance than the conventional XLPE systems. Although lots of analyses on chemical, mechanical and electrical

$\dagger$ Corresponding Author: Institute of High Voltage and High Current, Faculty of Electrical Engineering, Universiti Teknologi Malaysia, Malaysia. (mohdhafizi@fke.utm.my)

* Dept. of Electrical Engineering, Faculty of Engineering, Universitas Andalas, Indonesia. (aulia007@gmail.com)

** Institute of High Voltage and High Current, Faculty of Electrical Engineering, Universiti Teknologi Malaysia, Malaysia. (zulkurnain@utm.my)

Received: July 23, 2015; Accepted: December 9, 2015 characteristics of polymer blends and nanocomposites have been carried out $[10,11]$, analyses on partial discharge characteristics of polymer blends and composites were scarce. Specifically, partial discharge characteristics of linear low density polyethylene-natural rubber (LLDPE/ NR) blends were less discussed in the literature.

From the work of Makmud et al. [12, 13], partial discharge characteristics of LLDPE/NR blend, investigated using CIGRE method II, were found to depend on the ratio of the blend. Furthermore, polymer nanocomposites are fabricated by adding uniformly dispersed nanosized filler into the polymer matrix. The nanosized filler is typically added to the matrix in small quantity which is less than 10 $\mathrm{wt} \%$. Adding more than $10 \mathrm{wt} \%$ of nanofiller is considered uneconomical for mass production since the commercial nanofillers are very expensive [14]. Also, at higher weight percentage of nanofiller amount, they tend to be agglomerated thereby nullifying the beneficial effect of nanoparticles [15]. In this work, partial discharge patterns of LLDPE/NR filled with $5 \mathrm{wt} \%$ of ATH nanofiller were analyzed along with morphological analyses using a scanning electron microscope (SEM). When the electric field was increased from zero to a maximum value, phase position changes of partial discharge events around the zero area were discussed.

\section{Experimental Procedure}

\subsection{Sample preparation}

The compositions of the prepared samples are tabulated 
Table 1. Sample composition in weight percentage (wt \%)

\begin{tabular}{c|c|c|c}
\hline Sample Name & LLDPE & NR & ATH \\
\hline A & 100 & 0 & 5 \\
\hline B & 90 & 10 & 5 \\
\hline C & 80 & 20 & 5 \\
\hline D & 70 & 30 & 5 \\
\hline
\end{tabular}

in Table 1. The LLDPE/NR blends were made up of NR with different compositions, ranging $0 \mathrm{wt} \%-30 \mathrm{wt} \% .5$ wt $\%$ of alumina trihydrate was added to the blends for enhancing surface tracking resistance [16]. The samples were blended using a two-roll mill mixer for 15 minutes at a temperature of $180{ }^{\circ} \mathrm{C}$. Each sample was then molded by using a melt compression method at $160{ }^{\circ} \mathrm{C}$, prior to cooling down at room temperature.

\subsection{Experimental setup}

Fig. 1 illustrates the experimental setup for partial discharge testing. A CIGRE method II standard test cell (as also shown in Fig. 2) was used to house a test sample. A current transducer was used to detect partial discharge activities within a frequency range of $20 \mathrm{kHz}$ to $80 \mathrm{kHz}$.

A picoscope was used to acquire partial discharge and power supply signals. The output of the picoscope was connected to a netbook via a USB port using the LabVIEW interface. The main function of the netbook was for logging partial discharge monitoring data. Partial discharge data were then captured, saved and analyzed using a program developed based on the LabVIEW software. For safety purposes, a high voltage (HV) resistor and a sphere gap were used to protect the HV transformer and the measuring equipment (the picoscope and the netbook) respectively

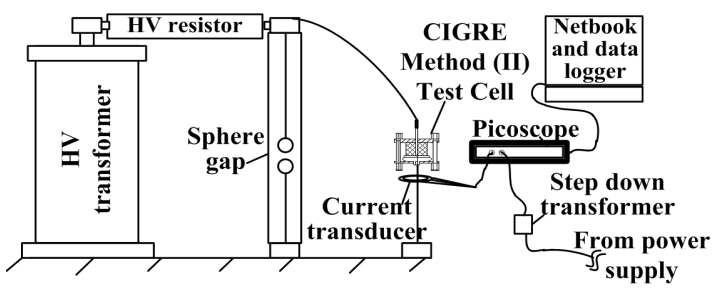

Fig. 1. Circuit arrangement for partial discharge measurement

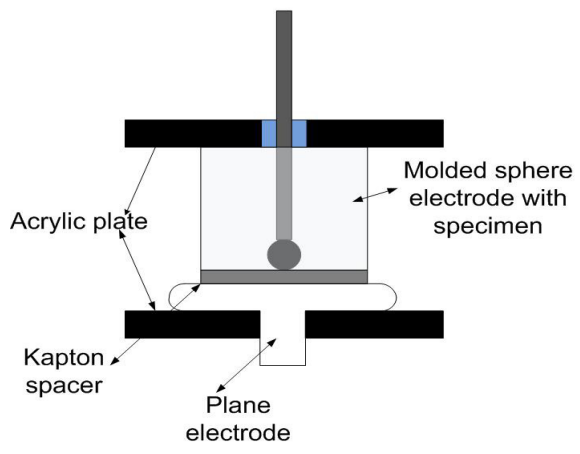

Fig. 2. CIGRE Method (II) Test Cell

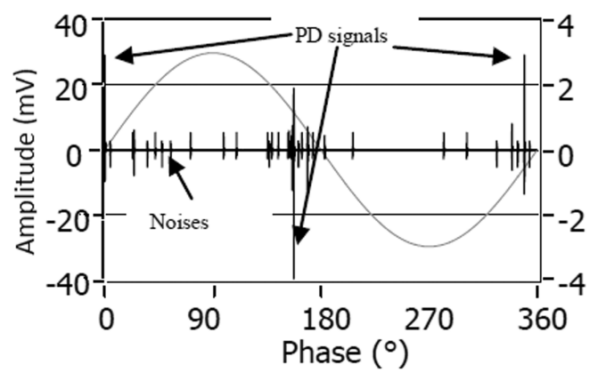

Fig. 3. Partial discharge waveform with noise

from over-current in case of breakdown during testing.

For the LabVIEW software, a sampling rate of $125 \mathrm{kS} / \mathrm{s}$ was used and data were saved if a threshold voltage of 20 $\mathrm{mV}$ was recorded. Each partial discharge file contains 2500 data sets, equivalent to $20 \mathrm{~ms}$ recorded data that represents a full cycle of a $50 \mathrm{~Hz}$ sinusoidal waveform.

The first 625 data sets represent the phase angle between $0-90^{\circ}$, the second subsequent 1250 data sets represent the phase angle between $90^{\circ}-180^{\circ}$, the third subsequent 1875 data sets represent the phase angle between $180^{\circ}-270^{\circ}$, and the final subsequent 2500 data sets represent the phase angle between $270^{\circ}-360^{\circ}$. Partial discharge signals were recorded continuously for one hour at $6.5 \mathrm{kV} \mathrm{AC}$ applied voltage. Analysis for partial discharge patterns was done after the experiment via the LabVIEW block program that had taken a highest value between the 1st data set and the $626^{\text {th }}$ data sets, and also between the $1875^{\text {th }}$ data sets and $2500^{\text {th }}$ data set. Other highest values were taken between the $626^{\text {th }}$ and $1875^{\text {th }}$ data sets, as shown in Fig. 3.

\subsection{Partial discharge calibration}

To obtain exact values of charges from partial discharge testing, partial discharge equipment needs to be calibrated. In this work, the calibration was performed using the Partial Discharge Charge Calibrator Type 450 manufactured by Haefely. The Picoscope was calibrated by injecting the point of measurement with five different pulse charges, i.e., $5 \mathrm{pC}, 10 \mathrm{pC}, 20 \mathrm{pC}, 50 \mathrm{pC}$ and $100 \mathrm{pC}$, and the results were compared with the literature [12]. For example, a partial discharge magnitude of $200 \mathrm{mV}$ was found to be equivalent to $20 \mathrm{pC}$. The ratio between the reading in $\mathrm{mV}$ and $\mathrm{pC}$ was maintained at a ratio $10: 1$. It is noteworthy that the charge sensitivity of the partial discharge detection system is $2 \mathrm{pC}$, based on a fixed threshold voltage of 20 $\mathrm{mV}$. Therefore, signals with charges above $2 \mathrm{pC}$ are considered as partial discharge signals.

\section{Results and Discussion}

\subsection{Partial discharge trend}

Partial discharge number and magnitude characteristics 
of samples A, B, C and D were shown from Fig. 4 until Fig. 7 , respectively. The partial discharge data were collected and plotted at a time interval of 10 minutes. From the obtained results, the highest partial discharge numbers were recorded for sample $\mathrm{C}$ during the first 10-minute interval. This was followed by samples A, D and B. In other words, among all investigated samples, sample B had the lowest partial discharge magnitudes and partial discharge numbers, and is therefore a sample with optimum partial discharge resistance characteristics. It should be noted that the partial discharge behaviours represent a transition time between zero crossings of the electric field inside a void into a certain amount of electric field. Also, it can represent physical processes inside a void. In the CIGRE method II test cell configuration shown in Fig. 2, there is a space or void of $0.1 \mathrm{~mm}$ between the high voltage electrode and the insulation layer. When a high voltage is applied to the electrode, the void, which is usually filled with normal air, is bombarded by electrons, causing the void to be filled with new gases with a higher pressure, causing the breakdown threshold voltage within the void to increase. This reduces the discharge rate inside the void. Also, different materials will generate different gases and different pressures inside a void [17].

Moreover, it was noticed that, positive partial discharge magnitudes and positive partial discharge numbers exhibited

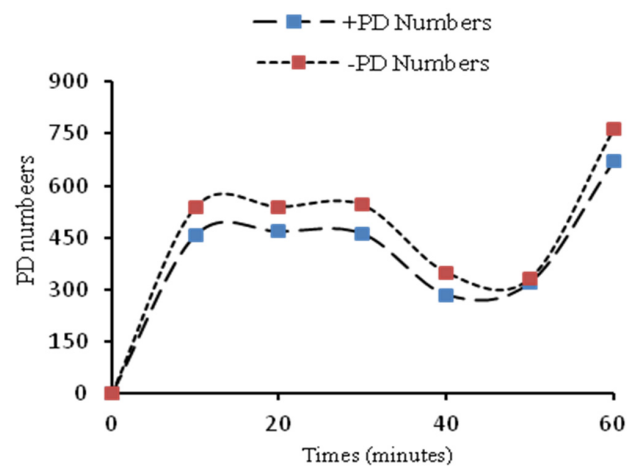

(a)

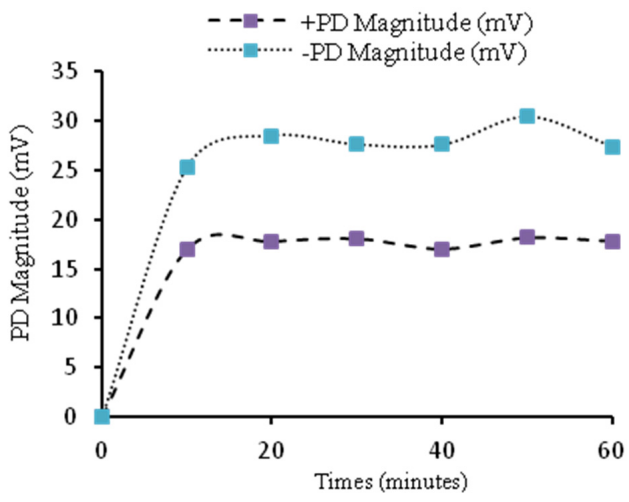

(b)

Fig. 4. PD characteristics of sample A; (a) PD number, (b) PD magnitude

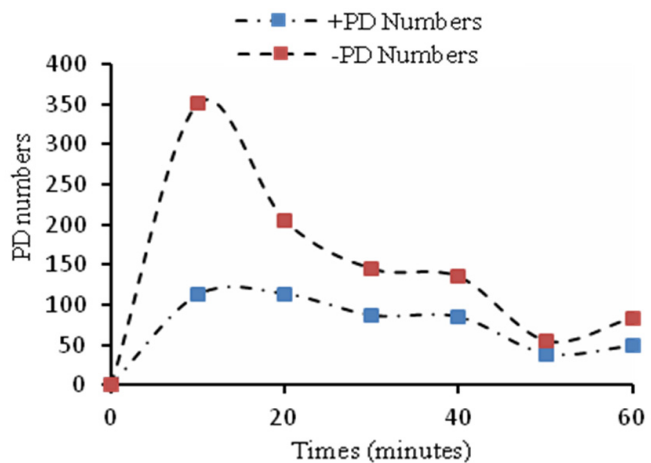

(a)

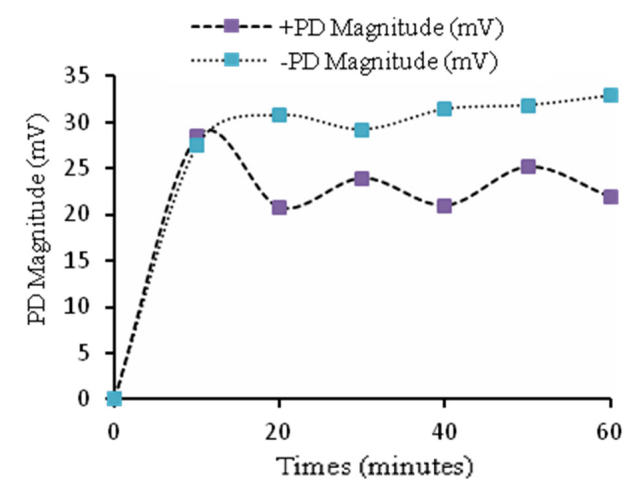

(b)

Fig. 5. PD characteristics of sample B; (a) PD number, (b) PD magnitude

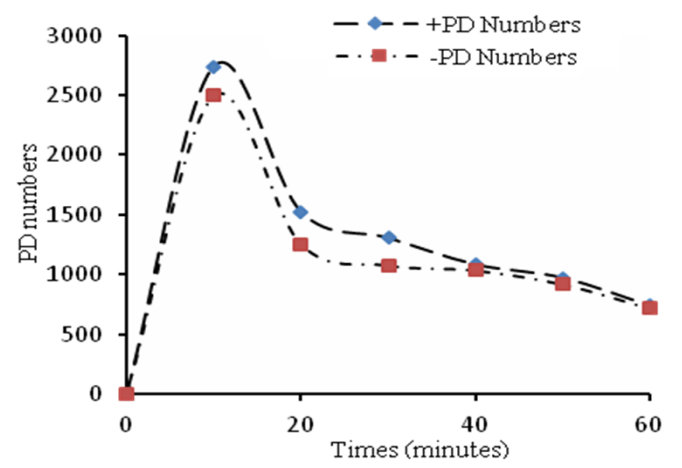

(a)

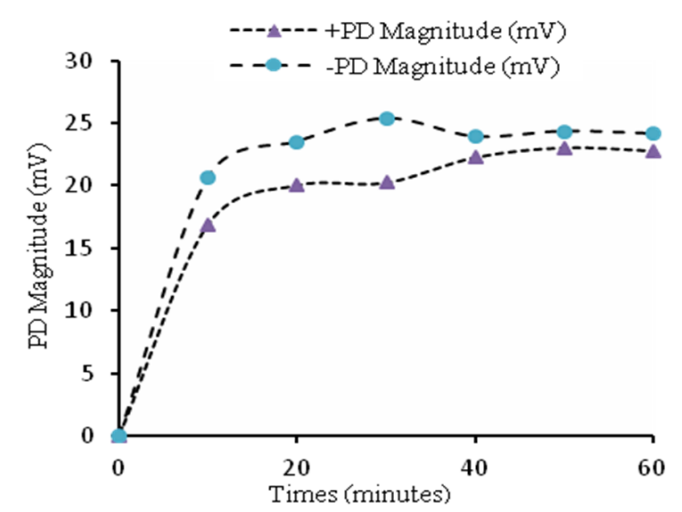

(b)

Fig. 6. PD characteristics of sample $C$; (a) PD number, (b) PD magnitude 
small changes or almost constant values in almost all samples. This constant condition could be due to the insufficient electric field that was needed to create new discharges. However, the negative partial discharge magnitudes and partial discharge numbers depicted a reduction as a function of time. This condition could be elucidated by referring to the material composition effects. In sample B specifically, the addition of $10 \%$ of NR and $5 \%$ of ATH filler contributed to the enhancement of partial discharge resistance due to its stiffness and elasticity characteristics which help to trap the charge and filled in the void gaps. However, when the number of NR increased, it seems to attract more partial discharge activities due to an increase in the number of pores that could be a major drawback for insulating materials.

In case of partial discharge magnitudes, sample $\mathrm{C}$ had the highest total partial discharge magnitudes, followed by samples A, D and B. The higher PD magnitude was contributed by the partially high gas pressure and high temperature produced by partial discharges inside the void, thereby leading to a high magnitude of partial discharge. Also, partial discharges produced space charges that strengthen the local electric field in the voids, thus maintaining a continuous development of partial discharge

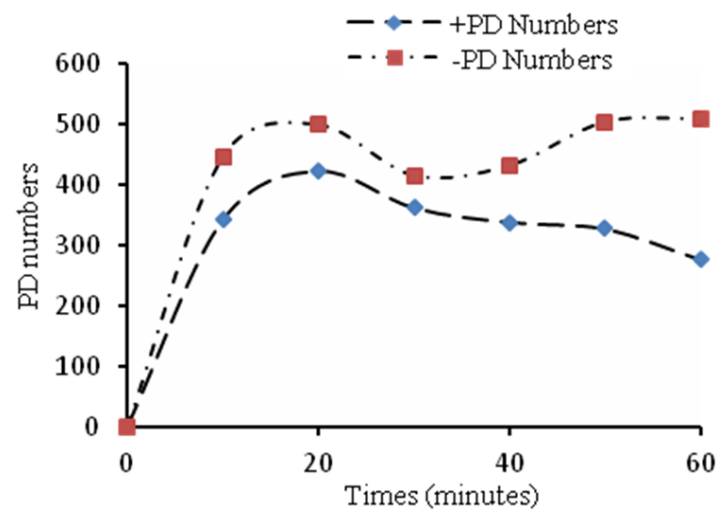

(a)

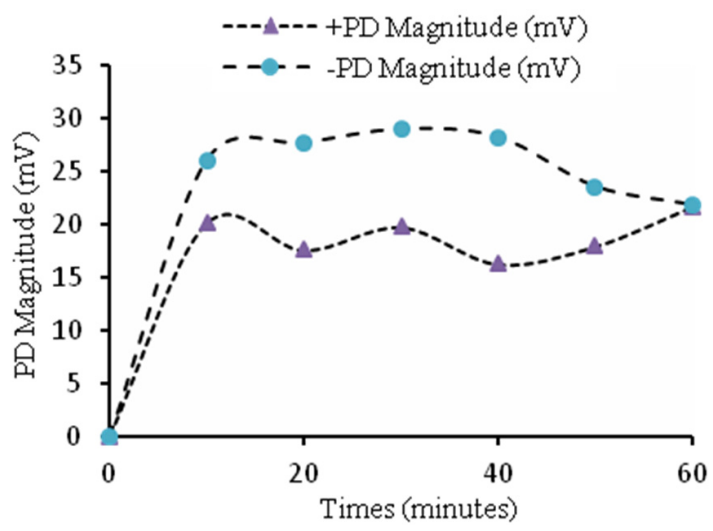

(b)

Fig. 7. PD characteristics of sample D; (a) PD number, (b) PD magnitude to form more abrupt and partially changes of partial discharge patterns [18].

\subsection{Phase-resolved partial discharge patterns}

Partial discharge characteristics of the investigated samples were further analyzed by taking into account the respective phase resolved partial discharge patterns. Fig. 8

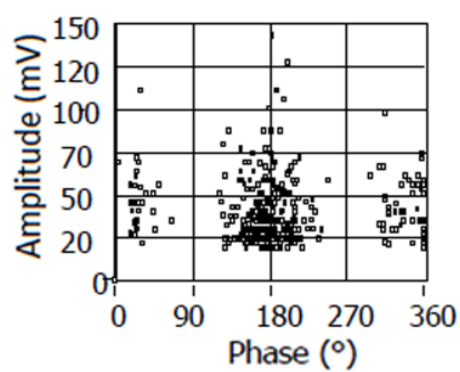

(a)

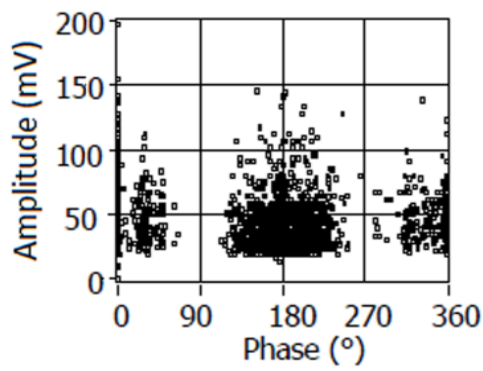

(b)

Fig. 8. PD pattern of sample A (a) after 10 minutes, (b) after 60 minutes

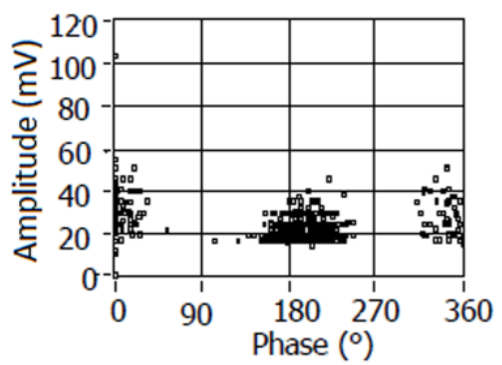

(a)

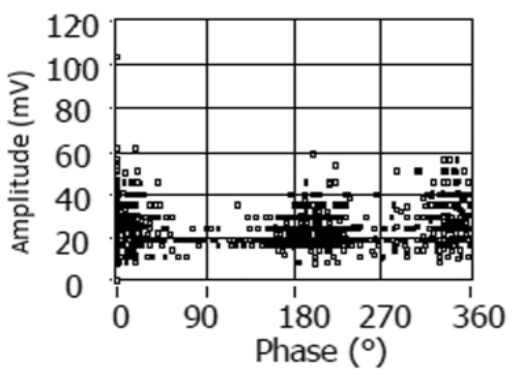

(b)

Fig. 9. PD pattern of sample B (a) after 1 minutes, (b) after 60 minutes 
to Fig. 11 illustrate the phase-resolved partial discharge patterns of samples A, B, C and D, respectively at the first 10 minutes and at the maximum test duration of 60 minutes. All the highest magnitude is located at the zero crossing area where the partial discharge events take place. In the first 10 minutes, all partial discharge magnitudes were below $60 \mathrm{mV}$, and the highest partial discharge magnitude was about $160 \mathrm{mV}$ (see Fig. 11(a)). The phase positions of

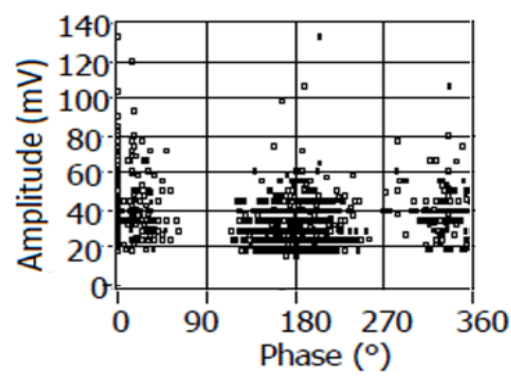

(a)

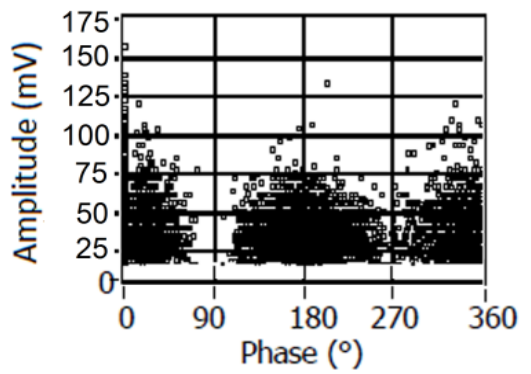

(b)

Fig. 10. PD pattern of sample $C$ (a) after 10 minutes, (b) after 60 minutes

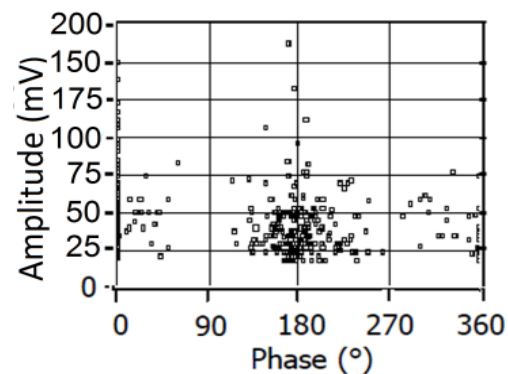

(a)

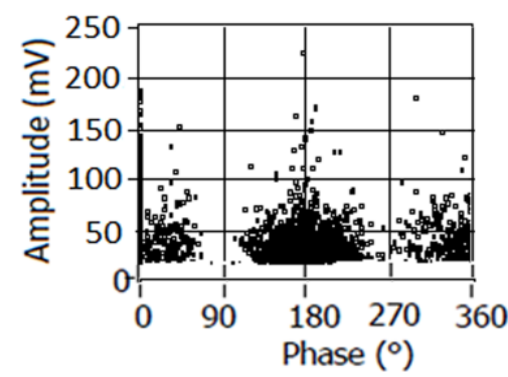

(b)

Fig. 11. PD pattern of sample D (a) after 10 minutes, (b) after 60 minutes partial discharge events were located around zero area where the electric field changed from zero and reached its maximum value fetching.

At 60 minutes of partial discharge measurement, partial discharge activities were dense especially in sample $\mathrm{C}$, thereby showing the relationship between $\mathrm{PD}$ and aging times. Therefore, it can be interpreted that partial discharge activities degraded an insulating material, resulting in more micropores, oxidative decomposition, by-products deposition, and uneven congregating state caused by partially hot temperature and high pressure produced from PD thereby causing the wall of the micropores to be softened and created the burst between those walls $[18,19]$.

\subsection{Scanning electron microscopy analysis}

Scanning electron micrographs of the investigated samples before and after partial discharge testing are shown from Fig. 12 until Fig. 14. It is understood that the surface of the material is affected by partial discharge activities during the testing. Some microsized damages caused by partial discharge activities were found and it was identified as by-products due to material decomposition. This is shown as red circled regions of Fig. 12(b), Fig. 13(b) and Fig. 14(b). Under an applied voltage, partial

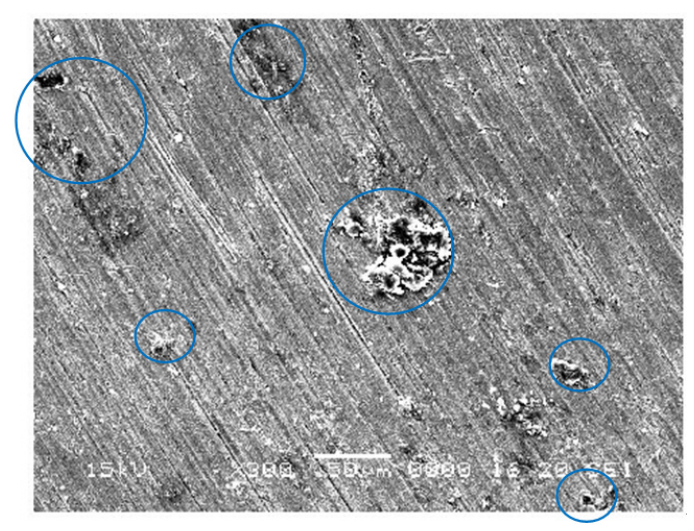

(a)

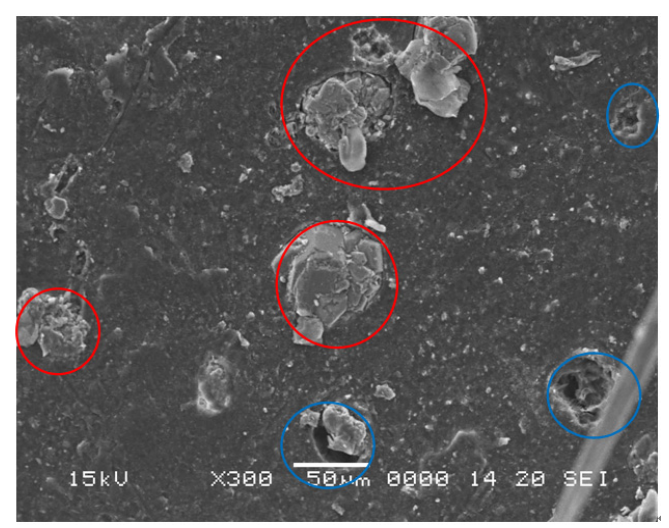

(b)

Fig. 12. Sample B (a) before PD test, (b) after PD test 


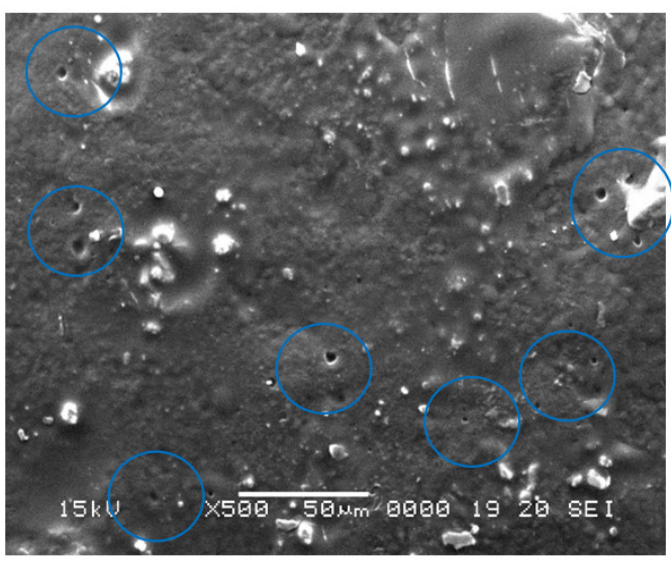

(a)

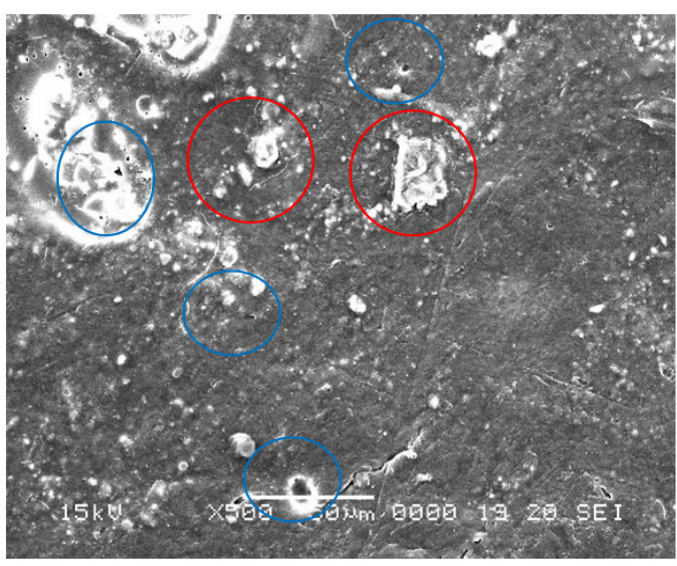

(b)

Fig. 13. Sample C (a) before PD test, (b) after PD test

discharges induce gas pressure centralization and increase the temperature process. Thus, promoting the existence of by-products by decomposition of polymer chain due to partial high pressure and hot temperature [7, 20,21].

Furthermore, an increased amount of micropores was found in samples with higher content of NR. The micropores attracted more PD activities. Likewise, after some of the micropores are broken through, the macrospores are created and thereby increasing the number of PD activities inside the NR vicinity. Micropores could therefore be one of the primary factors that weaken the insulating material, resulting in the working electric field to become maximal, which eventually lead to the complete breakdown of insulation [18].

It can be seen that micropores increased in sample D (Fig. 14) which had more NR content compared to sample B (Fig. 12). The micropores were circled in blue in Fig. 12, Fig. 13 and Fig. 14. The micropores might increase the gas pressure in the NR vicinity. Under an applied voltage, discharges that occur inside micropores may induced ionization, resulting in a high temperature and a high pressure at the pores' vicinity, thus softening and weakening the insulation. On the other hand, the area

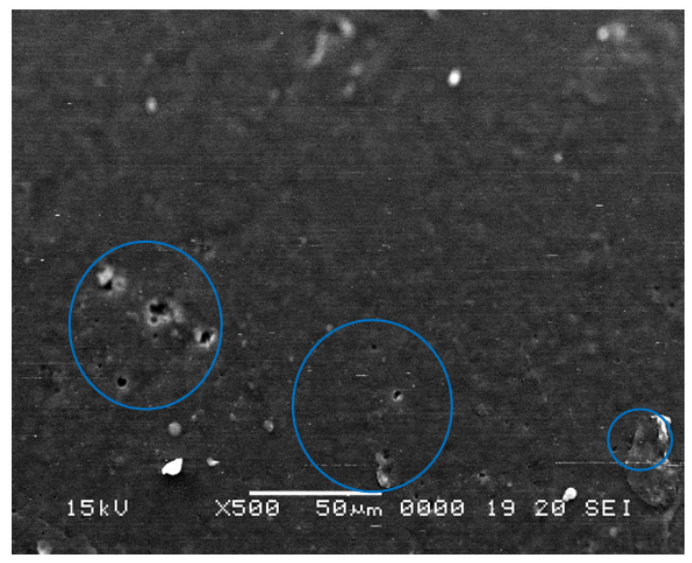

(a)

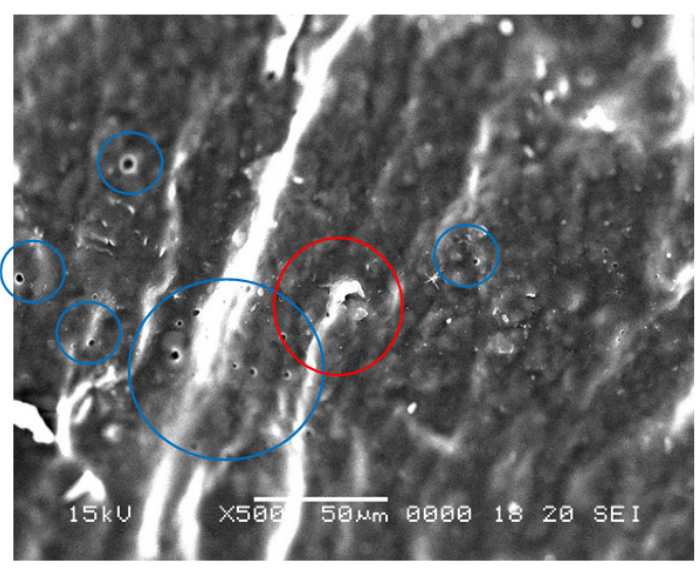

(b)

Fig. 14. Sample D (a) before PD test, (b) after PD test

around the high voltage tip of electrode suffers more damages compared to the area outside the electrode in the same sample.

\section{Conclusion}

The results showed that different weight percentages of an NR addition to LLDPE had effects on the partial discharge resistance of the resulting material. Specifically, the test sample B, i.e., LLDPE with $10 \mathrm{wt} \%$ of NR showed improved partial discharge resistance. Each material composition responded differently to high electric field stresses, and the partial discharge pattern analysis showed that there was no significant effect in terms of partial discharge phase of occurrences. In addition, the test sample $B$ showed the lowest PD values for the first 10 minutes and the $\mathrm{PD}$ reading taken after 60 minutes. Morphological studies using SEM showed that an increase in the NR weight percentage improved surface roughness of the resulting material, but some porosity was detected. The differences between the samples' surfaces before and after partial discharge testing indicated damages on the sample's 
surface caused by the tip electrode.

\section{Acknowledgements}

This work was supported by the Universiti Teknologi Malaysia and Malaysia's Ministry of Higher Education (MoHE) under grants Fundamental Research Grant Scheme (R.J130000.7809.4F599) and Research University Grant (Q.J130000.2609.10J87).

\section{References}

[1] T. K. Abdel-Galil, R. M. Sharkawy, M. M. a. Salama, and R. Bartnikas, "Partial discharge pulse pattern recognition using an inductive inference algorithm," IEEE Transactions on Dielectrics and Electrical Insulation, vol. 12, pp. 320-327, 2005.

[2] C. S. Kim, T. Kondo, and T. Mizutani, "Change in PD pattern with aging," IEEE Transactions on Dielectrics and Electrical Insulation, vol. 11, no. 1, pp. 13-18, 2004.

[3] K. D. Wolter, J. F. Johnson, and J. Tanaka, "Degradation product analysis for polymeric dielectric materials exposed to partial discharges," IEEE Transactions on Electrical Insulation, vol. EI-13, no. 5, pp. 327-336, 1978.

[4] T. Baumann, B. Fruth, F. Stucki, and H. R. Zeller, "Field-enhancing defects in polymeric insulators causing dielectric aging," IEEE Transactions on Dielectrics and Electrical Insulation, vol. 24, no. 6, pp. 1071-1076, 1989.

[5] F. H. Kreuger, E. Gulski, and A. Krivda, "Classification of partial discharges," IEEE Transactions on Dielectrics and Electrical Insulation, vol. 28, no. 6, pp. 917-931, 1993.

[6] G. J. Paoletti and A. Golubev, "Partial discharge theory and technologies related to medium-voltage electrical equipment," IEEE Transactions on Industry Applications, vol. 37, no. 1, pp. 90-103, 2001.

[7] S. Boggs, "Partial discharge: overview and signal generation," IEEE Electrical Insulation Magazine, vol. 6, no. 4, 1990.

[8] G. Katsuta, A. Toya, K. Muraoka, T. Endoh, Y. Sekii, and C. Ikeda, "Development of voltage a method of partial discharge detection in extra-high cross-linked polyethylene insulated cable lines," IEEE Transactions on Power Delivery, vol. 7, no. 3, pp. 10681079, 1992.

[9] B. X. Du, Z. L Ma, Y. Gao, and T. Han, "Effect of temperature on electrical tree in silicone rubber," IEEE International Conference on Solid Dielectrics, pp. 1-4, 2010.

[10] M. A. M. Piah, A. Darus, and A. Hassan, "Electrical tracking performance of LLDPE-natural rubber blends by employing combination of leakage current level and rate of carbon track propagation," IEEE Transactions on Dielectrics and Electrical Insulation, vol. 12, no. 6, pp. 1259-1265, 2005.

[11] Y. Arief, I. Ismail, M. Makmud, A. Sayuti, Z. Adzis, and N. A. Muhamad, "Partial discharge characteristics of natural rubber blends with inorganic nanofiller as electrical insulating material," Applied Mechanics and Materials, vol. 284-287, pp. 188-192, 2013.

[12] M. Z. H. Makmud, Y. Arief, and M. Wahit, "Partial discharge characteristics with morphological analysis and tensile properties of linear low-density polyethylene-natural rubber blends", International Journal on Electrical Engineering and Informatics, vol. 3, no. 4, pp. 431-440, 2011.

[13] M. Z. H. Makmud, Aulia, Y. Z. Arief, and M. U. Wahit, "Ageing and degradation mechanism of linear low density polyethylene-natural rubber composites due to partial discharge," IEEE International Conference on Power and Energy, pp. 985-989, 2012.

[14] N. A. M. Jamail, M. A. M. Piah, N. A. Muhamad, R. A. Zainir, N. F. Kasri, and Q. E. Kamarudin, "DC conductivity of polymer nanocomposites for different types and amount of nanofiller," International Journal of Electrical Engineering and Informatics, vol. 5, no. 2, pp. 217-225, 2013.

[15] T. Andritsch, "Epoxy based nanodielectrics for high voltage DC - applications - synthesis, dielectric properties and space charge dynamics," PhD Dissertation, TU Delft, 2010.

[16] Y. Sekii, "Degradation of low-density polyethylene and cross-linked polyethylene by partial discharge," IEEE Transactions on Dielectrics and Electrical Insulation, vol. 17, pp. 116-124, 2010.

[17] T. Tanaka, "Internal partial discharge and material degradation," IEEE Transactions on Electrical Insulation, vol. EI-21, no. 6, pp. 899-905, 1986.

[18] X. Zheng and G. Chen, "Propagation mechanism of electrical tree in XLPE cable insulation by investigating a double electrical tree structure," IEEE Transactions on Dielectrics and Electrical Insulation, vol. 15, no. 3, pp. 800-807, 2008.

[19] R. Bartnikas, "Partial discharges their mechanism, detection and measurement," IEEE Transactions on Dielectrics and Electrical Insulation, vol. 9, no. 5, pp. 763-808, 2002.

[20] H. Illias, "Measurement and simulation of partial discharges within a spherical cavity in a solid dielectric material," PhD Dissertation, University of Southampton, 2011.

[21] S. S. Bamji, A. T. Bulinski, and R. J. Densley, "The role of polymer interface during tree initiation in LDPE," IEEE Transactions on Electrical Insulation, vol. EI-21, no. 4. pp. 639-644, 1986. 


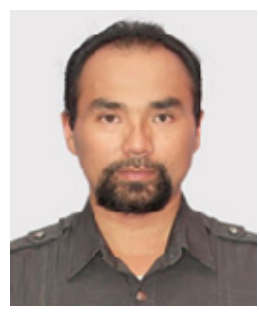

Aulia He received Bachelor degree (S.T.) in electrical engineering from Sriwijaya University, Palembang, Indonesia and Master degree (M. Eng) in 2009 from Universiti Teknologi Malaysia (UTM). He is a lecturer in Andalas University, Padang, Indonesia. Currently, he is a $\mathrm{PhD}$ student in Institute of High Voltage and High Current, Faculty of Electrical Engineering, UTM. His research interests are PD related issues in an insulator, new nanocomposite material for insulator, the lightning detection and mapping system.

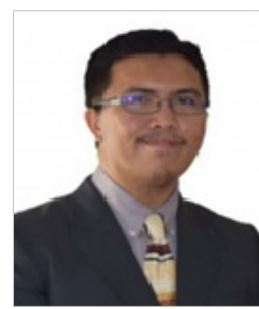

Mohd Hafizi Ahmad He received his B. Eng. and $\mathrm{PhD}$ degrees in Electrical Engineering from UTM, Malaysia in 2009 and 2013 respectively. Formerly, he was visiting researcher in the University of Leicester, UK, Sriwijaya University, Indonesia and Tanjungpura University, Indonesia within 2010 and 2012. He worked as a tutor in the Faculty of Electrical Engineering, UTM from 2009-2013. Currently, he works as a senior lecturer in the Institute of High Voltage and High Current, Faculty of Electrical Engineering, UTM. His research interests cover different types of high voltage insulation (solid, liquid and gas), nanodielectrics, insulation performance and breakdown of dielectric materials.

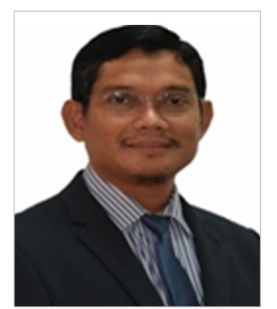

Zulkurnain Abdul-Malek He obtained B. Eng degree from Monash University (Melbourne) in 1989 and his MSc and PhD degrees from University of Wales Cardiff in 1995 and 1999 respectively. Since 1989, he has been a member of the Electrical Engineering Faculty at UTM. He is currently a Professor and the Director of UTM Institute of High Voltage and High Current. His research interests include intelligent condition monitoring of $\mathrm{HV}$ equipment, lightning detection and warning systems, nanodielectrics and fast transient response of high voltage surge arresters.

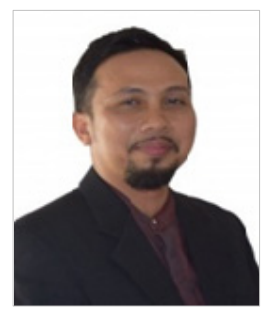

Yanuar Z. Arief He obtained B. Eng. degree from Tanjungpura University, Indonesia in 1994. Also, he received the M. Sc. degree from the Bandung Institute of Technology, Indonesia in 1998 and $\mathrm{PhD}$ from Kyushu Institute of Technology, Japan in 2006 and also Post-Doctoral from University of Siegen, Germany. Currently, he is a senior lecturer in the Institute of High Voltage and High Current, Universiti
Teknologi Malaysia, Johor, Malaysia. His research interests include partial discharge detection and degradation phenomena of polymeric insulating materials.

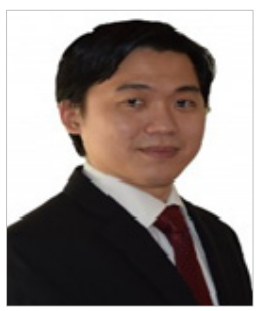

Kwan Yiew Lau He received his B. Eng. degree in electrical engineering from Universiti Teknologi Malaysia in 2007. After working as an electronics development engineer at Dyson Malaysia, he joined the Faculty of Electrical Engineering, Universiti Teknologi Malaysia, as a tutor in 2008. He then completed his MEng degree in electrical power engineering at the same university in 2010. Later in 2013 he received his $\mathrm{PhD}$ degree in electronics and electrical engineering from the University of Southampton, UK. He is now a senior lecturer at the Institute of High Voltage and High Current, Faculty of Electrical Engineering, UTM. His research interests include $\mathrm{HV}$ engineering, dielectric materials, and renewable energy systems.

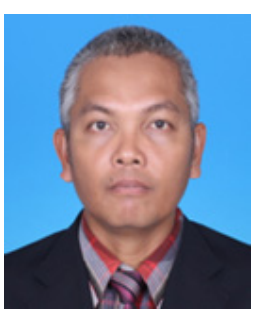

Novizon Novizon received Bachelor's degree in electrical engineering from Sriwijaya University, Palembang, Indonesia, in 1993 and the Master degree in electrical engineering from Universiti Teknologi Malaysia, in 2010 $\mathrm{He}$ is currently pursuing the $\mathrm{PhD}$ degree in the High Voltage and High Current Institute, Faculty of Electrical Engineering, UTM. Since 1997, he has been a senior lecturer in Electrical Engineering Department, Andalas University, Padang, Indonesia. His research interests cover HV related issues, condition monitoring of HV equipment, HV surge arresters, lightning detection and mapping system. 